\title{
The use of medication after laparoscopic anti-reflux surgery
}

\author{
Abdulzahra Hussain · Tarun Singhal • \\ Hussein Almusawy $\cdot$ Shamsi EL-Hasani
}

Published online: 26 February 2010

(C) Springer Science+Business Media, LLC 2010

\section{Dear Sir}

We read with great interest the article entitled, "The Use of Medication after Laparoscopic Antireflux Surgery" [1]. We congratulate the authors for their results and great efforts; however, we have the following points that we think are complementary to the educational value of the study:

1. We understood from this study that all patients had routine postoperative gastroscopy, barium, and esophageal physiological studies. In doing so, the authors tried to prove the anatomical integrity of the hiatus.

We did not subject our patients to such studies unless they develop symptoms. We think it is unnecessary because there will be no abnormality detected except in few patients. These tests have resource implications and radiological exposure risk. On the other hand, there is poor correlation between postoperative symptoms and definite reflux [2]. There is no consensus on the question of how to treat asymptomatic patients who have mechanical failure of the antireflux surgery and the present study did not answer it. Obviously, symptomatic patients who have no abnormality on the investigations would need medications to control their symptoms [3].

2. Multidisciplinary approach to gastroesophageal reflux disease is a new concept, and to prove its efficacy we would need a comparative, well-matched group of patients, otherwise it will be of no clinical advantage.

3. The authors reported excellent results in the first year. Follow-up of the patients during the postoperative 5 years could provide vital evidence of the efficacy and durability of the procedure.

4. Two techniques have been used: classical Nissen and posterior partial plication. This would influence the outcome and every procedure has its own characteristics.

We will appreciate kind comments from the authors regarding these points.

Disclosures Drs. Abdulzahra Hussain, Tarun Singhal, Hussein Almusawy, and Shamsi EL-Hasani have no conflicts of interest or financial ties to disclose.

\section{References}

1. Ciovica R, Riedl O, Neumayer C, Lechner W, Schwab GP, Gadenstätter M (2009) The use of medication after laparoscopic antireflux surgery. Surg Endosc 24:1938-1946

2. Khajanchee YS, O'Rourke RW, Lockhart B, Patterson EJ, Hansen PD, Swanstrom LL (2002) Postoperative symptoms and failure after antireflux surgery. Arch Surg 137:1008-1013

3. Khajanchee YS, O'Rourke R, Cassera MA, Gatta P, Hansen PD, Swanström LL (2007) Laparoscopic reintervention for failed antireflux surgery: subjective and objective outcomes in 176 consecutive patients. Arch Surg 142:785-901 